\title{
Penetration of a Small Caliber Projectile into Single and Multi-layered Targets
}

\author{
M.A.Abdel-Wahed ${ }^{1}$, A.M.Salem ${ }^{2}$, A.S.Zidan ${ }^{3}$ and A.M.Riad ${ }^{4}$ \\ ${ }^{1}$ Military technical college,Cairo,Egypt, medo4042@gmail.com \\ ${ }^{2}$ Military technical college,Cairo,Egypt,AMSalem@gmail.com \\ ${ }^{3}$ Military technical college,Cairo, Egypt, megdzidan@yahoo.com \\ ${ }^{4}$ Military technical college,Cairo,Egypt, ahmed_riad10@hotmail..com
}

\begin{abstract}
The normal penetration of armor-piercing projectiles into single and multi-layered steel plates has been investigated. An experimental program has been conducted to study the effect of spaced and in-contact layered targets on their ballistic resistance. Armor piercing projectiles with caliber of $7.62 \mathrm{~mm}$ were fired against a series of single and multi-layered steel targets. The projectile impact velocities were ranged from $300-600 \mathrm{~m} / \mathrm{s}$, whereas the total thicknesses of the tested single, spaced and in-contact layered steel targets were $3 \mathrm{~mm}$. The penetration process of different tested target configurations has been simulated using Autodayn-2D hydrocode.

The experimental measurements of the present work were used to discuss the effect of impact velocity, target configurations and number of layers of different spaced and in-contact layered steel targets on their ballistic resistance. In addition, the post-firing examination of the tested targets over the used impact velocity range showed that the single and each layer of spaced and in-contact laminated steel targets were failed by petalling. Finally, the obtained experimental measurements were compared with the corresponding numerical results of Autodyn-2D hydrocode, good agreement was generally obtained.
\end{abstract}

Keywords: [penetration, multi-layered targets, ballistic resistance, dynamic plasticity, and numerical simulation]

\section{INTRODUCTION}

The penetration phenomenon of a projectile into single and multi-layered targets is of interest in many applications. Backman and Goldsmith [1] and Zukas [2] have reviewed studies which deal with experiments, analytical models and nuermical simulations for determining the ballistic limit of different target configurations and the residual velocity of projectiles for impact velocities greater than the balistic limit.

Efforts have been recently directed towards developing analytical models and software packages to predict/simulate the response of single and multi-layered targets subjected to penetration. The analytical models are based on energy balance and/or momentum conservation along with certain simplifying assumptions [3-5], whereas the developed software packages investigate the ballistic penetration of different target configurations using piece wise (finite element) or point wise (finite difference) techniques [6-7].

The benefits of using multi-layered metallic targets of equal thickness to the single targets are not clear yet. Almohandes et al. [8] studied experimentally the effect of target configurations on their ballistic performance when they impacted by $7.62 \mathrm{~mm}$ standard bullets of different velocities. First, single steel plates, 1-8 mm thick, were tested, and the effect of thickness and mechanical properties of plate material were explored. Second, in-contact layered comprising an $8 \mathrm{~mm}$-thick steel target and spaced layered of the same total thickness, with spacing distances equal to or multiples of the bullet core diameter, were tested and the effect of number, thickness, and arrangement of layers were sought. They found that: (a) The monolithic steel targets were more effective than in-contact and spaced layered targets of the same total thickness, (b) The difference in effectiveness diminished with increasing impact velocity, and (c) Resistance of laminated steel targets increased as the number of layer decreased, and the thickness of back plate increased.

This is an Open Access article distributed under the terms of the Creative Commons Attribution-Noncommercial License 3.0, which permits unrestricted use, distribution, and reproduction in any noncommercial medium, provided the original work is properly cited. 
Dey et al. [9] investigated experimentally and numerically the ballstic perforation resistance of doublelayered steel plates impacted by blunt and ogival nosed projectiles. In their tests, $12 \mathrm{~mm}$-thick (monolithic or layered) targets of Weldox $700 \mathrm{E}$ were impacted by $20 \mathrm{~mm}$ projectiles at sub-ordnance velocity range. The ballistic limits of different target combinations were determined. In addition, they also simulated the penetration process of the tested target combinations by different projectiles using Ls-Dyna code. They found that: (a) The predicted ballistic limit of each target combination was in good agreement with that determined by experiment, and (b) A large ballistic limit was offered by double-layered systems when impacted by blunt projectiles.

Gupta and Madhu [10] investigated experimentally the normal and oblique impact of armour-piercing projectiles into single and layered plates made of mild steel, Rolled Homogenous Armor (RHA) and aluminum, respectively. Their projectiles were fired with impact velocities in the range $800-880 \mathrm{~m} / \mathrm{s}$. Their plate thickness varied in the range $4.7-40 \mathrm{~mm}$ and the ratio of the plate thickness to the projectile diameter varied in the range $0.75-6.5$ for single plates and up to 13 for layered plates. Their experimental measurements showed that the single plates were more effective than the in-contact layered targets which, in turn, were more effective than the spaced layered targets. They also derived a simple relation that could predict the target thickness capable of stopping their used projectile.

Yossifon et al. [11] developed an analytical model for penetration of multi-layered targets by rigid projectiles using the single layer model described in Ref. [12]. Their analytical solution was developed for which the momentum equation was satisfied pointwise in the target region, while the boundary and continuity conditions were satisfied only approximately. They also assumed a single particular velocity field for all target layers. They focused on two cases of a multi-layered target: one consisting of materials which differed only by their hardnesses; and the other consisting of signifcantly different materials (RHA and Aluminium). The predictions of their analytical model were in good agreement with those of Autodyn2D hydrocode for both cases, independently of whether the hard layer was first or second.

Woodward and Cimpoeru [13] studied the perforation of in-contact layered aluminum alloy plates, which had variety of configurations, by flat-ended and conical nosed projectiles. They determined the ballistic limits of their tested layered plates and used the results to evaluate energy absorption mechanisms due to deformation and failure modes. They observed that the propensity to stretch and bend or to shear a plug was affected by the thickness of exit-side layer relative to the projectile diameter; plugging by shear mechanism was accompanied with thick exit-side layer. They developed an analytical model treating the perforation of layered plates in two-stage process. These were indentation on the impact side followed by plug shear for thick exit-side layer or dishing for thin exit-side layer. The model predicts the ballistic limits of their tested targets for both flat-ended and conical nosed projectiles. They concluded that the monolithic plates were equally or more effective than the laminates.

Liang et al. [14] developed an analytical model for prdicting the ballistic performance of multi-layered targets, based on the concepts of momentum conservation, impulse-momentum equation and energy balance. Experimental measurements of Almohandes et al. [8] were used to validate the predictions of their model. For impact velocities ranged from $700-800 \mathrm{~m} / \mathrm{s}$ and projectile aspect ratio of 4.2 , good agreement was obtained between their predicted residual velocities and the corresponding experimental measurements of Ref. [8]. They also found that the ballistic performance was best for the double-layered target when the ratio of the first layer thickness to the total thickness was about 0.75 and the worst performance occured when this ratio was 0.5 . Myungsoo et al. [15] also studied numerically the optimization of multi-layered targets under ballistic impact using NET2D finite element code. They concluded that the target resistance increased with increasing thickness of first layer in multi-layered targets.

This paper is concerned with an experimental investigation of the effect of impact velocity, target configurations and number of layers on the ballsitic resistance of different multi-layered steel targets comparing with a monolithic target of equal total thickness. Moreover, comparison of predicted results of Autodyn-2D hydrocode and experimental measurements confined to plates exhibiting petalling failure is performed.

\section{EXPERI MENTAL WORK}

An experimental program has been conducted to study the normal perforation of a small caliber projectile into different configurations of spaced and in-contact multi-layered targets. The experimental facilities of 
the shooting range, Chair of Weapons and Ammunition, M.T.C, were used to investigate the ballistic resistance for a set of single and multi-layered steel targets against their penetration by $7.62 \times 39 \mathrm{~mm}$ armor-piercing projectiles. In general, the scheme of the experimental work includes the following activities: (a) characterization of the used steel plates for preparing the single and multi-layered steel targets, (b) ballistic tests and measurements, and (c) post-firing examinations.

\section{Characterization of the used steel plates}

Characterization of the steel plates was only concerned with the determination of their mechanical properties. Tensile tests were performed to determine the stress-strain behavior of the different thicknesses of steel plates. Standard tensile test specimens were prepared from steel plates with thicknesses of 1, 1.5, 2 and $3 \mathrm{~mm}$, respectively. Three tensile test specimens were prepared for each plate thickness.

A tensile test program was carried out on the tensile testing machine, Model MTS-810 with capacity of $100 \mathrm{kN}$, at loading rate of $50 \mathrm{~N} / \mathrm{sec}$. For each tested specimen, an extensometer was fixed on the center of its gauge length. The test speed, maximum load, and other test parameters were fed to the test program. After completing the specimen failure, the obtained data points were used to draw stress-strain behavior for each specimen.

\section{Ballistic Tests and Measurements}

Ballistic tests were performed in order to determine the projectile impact and post-perforating velocities for the different tested single and multi-layered steel targets, respectively. The principle of projectile velocity measurement was essentially based on measuring the time of its flight over a fixed distance (reference base). Breaking or connecting of electric circuits detected projectile arrival at a predetermined base. The measured velocity represented the velocity at the midpoint of the reference base; it was equal to the reference base divided by the measured time.

Projectile impact velocity was frequently measured at a close distance from point of impact. Because of the distance between the midpoint of reference base and target surface was small, the measured velocity was considered as the impact velocity of projectile. Projectile arrival was detected by the breaking of photocell electric circuits and the velocity measuring system could display the measuring time or projectile velocity directly on a PC screen.

The post-perforation velocity of the projectile was determined using velocity measuring frames. Each frame, which detected the projectile arrival, was connected to two-channel oscilloscope. When the projectile passed through each of the measuring frame, it connected an electric circuit and gave a signal to the oscilloscope. The time difference between the two signals was recorded and used to determine the projectile residual velocity.

The ballistic experiments were performed in the ballistic shooing range, which had provisions for the measurement of projectile impact and post-perforation velocities, respectively. As shown in Fig. 1, the ballistic set-up mainly consists of: ballistic rifle, impact velocity and post-perforation velocity frames with their respective electronic measuring instruments, and target mount.

$7.62 \times 39 \mathrm{~mm}$ armor-piercing projectiles having different impact velocities were fired against each prepared single and multi-layered steel targets; these velocities ranged from 300-600 m/s. The change in propellant charge mass was used to vary the projectile impact velocity. For each charge mass, a set of projectiles was fired against each tested target. Both the projectile impact and residual velocities, respectively, were measured using the velocity measuring systems used. Because of the barrel wear, close measurements of minimum two shots were considered; their average represented the projectile impact velocity. In addition, the average of the corresponding measured residual velocities was evaluated and taken as the projectile residual velocity.

Tested plates for the single and multi-layered steel targets with dimensions of $200 \mathrm{~mm} \times 200 \mathrm{~mm}$ were prepared. To avoid the influence of plate boundaries on the perforation process, projectiles were fired at the effective area of each target surface which was far from its boundaries. The distance between two perforations on the same target surface was $60 \mathrm{~mm}$ at least. Each target was perforated by a maximum of 4 shots. Symbols and digits are used to designate the tested targets. For example, $3 \mathrm{~mm}$ single represents a monolithic target with total thickness of $3 \mathrm{~mm}$. In addition, $1 \mathrm{~mm}+2 \mathrm{~mm}$ represents an in-contact double- 
layered steel target, consisting of $1 \mathrm{~mm}$-thick steel plate backed by $2 \mathrm{~mm}$-thick steel plate, whereas a $1 \mathrm{~mm}$ $+5 \mathrm{~S}+2 \mathrm{~mm}$ respresents the same double-layered steel target with $5 \mathrm{~mm}$ space in between.

\section{Post-Firing Examinations}

These were mainly concerned with the arrangement and the configurations of the set up, the projectile, and the target elements after perforation. After each firing test, the test set-up was examined to be sure that all connections were not damaged by projectile or its fragments and/or target splinters. Examining the recovered projectile after perforation of each tested target was very important in order to determine the degree of its deformation. This depended mainly on total thickness of the tested target and projectile impact velocity. For each tested single or multi-layered steel target, the petals height and its number as well as the perforation diameters of projectile into each plate were measured. All interesting features related to target failure mode and projectiles were photographed for the analysis of test results.

\section{NUMERICAL SIMULATION}

In the following, the experimental measurements of the ballistic tests were used to confirm the validity of the Autodyn-2D hydrocode predictions. Autodyn-2D hydrocode was used to simulate the perforation process due to the impact of a $7.62 \mathrm{~mm}$ armor-piercing projectile into each steel target configuration at each impact velocity used in the experimental program.

\section{Penetrator Simulation}

The used armor-piercing projectile has a caliber of $7.62 \mathrm{~mm}$. This projectile consists of penetrator and jacket. The penetrator is made of high strength steel with yield stress of $1500 \mathrm{MPa}$; it also has a diameter of $6.24 \mathrm{~mm}$, a length of $23.8 \mathrm{~mm}$ and an ogival nose with a hight of $9 \mathrm{~mm}$. In Autodyn-2D hydrocode, the penetrator was simulated to investigate its perforation process into single and different multi-layered steel targets, respectively. The input data of the penetrator material to the hydrocode are listed in Table 1. Moreover, the equation of state was selected to be linear, whereas no erosion model was selected. The equation of state is represented by [16]:

$$
\mathbf{P}=\mathbf{K} \boldsymbol{\mu},
$$

where $\mathrm{P}$ is the pressure, $\mu=\left(\left(\rho / \rho_{0}\right)-1\right)$, and $\mathrm{K}$ is the material bulk modulus.

Johnson-Cook equation represents the strength model for penetrator material; this equation defines the stress $\mathrm{Y}$ as [16]:

$$
Y=\left[A+B \epsilon_{p}{ }^{n}\right]\left[1+C \log \epsilon_{p}{ }^{*}\right]\left[1-T_{h}{ }^{m}\right]
$$

where $\mathrm{A}, \mathrm{B}, \mathrm{C}, \mathrm{n}$, and $\mathrm{m}$ are material constants, $\epsilon_{\mathrm{p}}$ is the effective plastic strain, $\epsilon_{\mathrm{p}}{ }^{*}$ is the normalized effective plastic strain rate, and $\mathrm{T}_{\mathrm{h}}$ is the homologous temperature which is expressed by:

$$
\mathbf{T}_{\mathrm{h}}=\left(\mathbf{T}-\mathbf{T}_{\text {room }}\right) /\left(\mathbf{T}_{\text {melt }}-\mathbf{T}_{\text {room }}\right),
$$

where $\mathrm{T}_{\text {room }}$ and $\mathrm{T}_{\text {melt }}$ are room and melting temperatures of penetrator material, respectively.

The expression in the first set of brackets of Eqn. (2) gives the stress as a function of strain when $\epsilon_{\mathrm{p}}{ }^{*}=1.0$ $\sec ^{-1}$ and $\mathrm{T}_{\mathrm{h}}=0$. The constant $\mathrm{A}$ is the basic yield stress at low strains whereas $\mathrm{B}$ and $\mathrm{n}$ represent the effect of strain hardening. The expressions in the second and third sets of brackets of the same equation represent the effects of strain rate and temperature, respectively.

\section{Target Plate Simulation}

The dimensions and material properties of each plate thickness that used in the eperimental program are fed into the hydrocode. These data are also listed in Table 1. For the material of each plate thickness, linear equation of state and erosion model of incremental geometric strain were selected. Johnson-Cook model was also selected to be a strength model of each plate thickness.

Figure 2 shows the simulated penetrator against spaced and in-contact triple-layered steel targets. The main procedures for simulating the penetrator and target into the Autodyn-2D hydrocode are [16]: (i) select suitable subgrids for penetrator and target, (b) choose Lagrange processor, (c) zoning the meshing (x, y) 
and mapping them by (I, J), (d) fill these meshes with its respective material data listed in Table 1, (e) set the initial conditions, (f) set the respective impact velocity of penetrator, (g) select the time step, (h) select a cycle limit and (i) run to initiate the execution of the perforation process.

\section{RESULTS AND DISCUSSIONS}

The present results are divided into: (i) results of plate material characterization, (ii) ballistic firing test results, (iii) post-firing examinations of tested single and multi-layered steel targets and recovered penetrators, and (iv) comparison between the experimental measurements and the corresponding predicted results of Autodyn-2D hydrocode.

\section{Results of Plate Material Characterization}

The stress-strain curve for each specimen of plate thicknesses was obtained. The obtained stress-strain curves for the different specimen thicknesses show that the values of strain to failure, yield strength and the tensile strength are closed. In addition, the relation between tensile stress and strain is non linear for each thickness of the tested specimens. Table 1 lists the average yied stress of the tested plate thciknesses. The elasticity modulus for each thickness of tested plates was deduced from its stress-strain behavior. The average value of elasticity modulus for the tested plate thicknesses are also listed in Table 1.

\section{Results of Ballistic Firing Tests}

The ballistic test results due to the impact of single and different multi-layered steel targets, with total thickness of $3 \mathrm{~mm}$, by small caliber penetrators having different impact velocities are presented. Both the penetrator residual velocity $\left(V_{r}\right)$, and velocity drop ratio $\left(D V / V_{i}\right.$, where $D V=V_{i}-V_{r}$ and $V_{i}$ is the impact velocity) are chosen to represent the ballistic resistance of constructed single and multi-layered steel target configurations to penetration.

In the following, samples of the ballistic test results due to the impact of constructed single and different multi-layered steel targets by small caliber penetrators having different impact velocities are presented. Figure 3 depicts the change of penetrator residual velocity with impact velocity for the single, spaced and in-contact triple-layered steel targets, having total thickness of $3 \mathrm{~mm}$. The present figure shows that the residual velocity increases with increasing impact velocity for each target configuration. In addition, the plotted results show that the ballistic resistance of single target is greater than that of the spaced and incontact triple-layered target configurations, except for $\mathrm{V}_{\mathrm{i}}>450 \mathrm{~m} / \mathrm{s}$ where the ballistic resistance of incontact triple-layered steel target is slightly greater than that of single steel target. The increase of space between the triple-layered steel targets decreases their ballistic resistance. This may be attributed to the small thickness of the individual penetrated layer and the absent of support during its penetration.

Figure 4 plots the change of penetrator residual velocity with impact velocity for the single, $(2 \times 1.5 \mathrm{~mm})$ spaced and in-contact double-layered steel targets, having total thickness of $3 \mathrm{~mm}$. For each target configuration, similar trends as that depicted in Fig. 3 for the increase of residual velocity with impact velocity are also obtained. Moreover, the plotted results show that the ballistic resistance of single and spaced double-layered steel targets is greater than that of the in-contact double-layered steel target. This may be attributed to the more penetrator energy dissipated during the penetration of front thick layer and no straining occurs to the backing layer of spaced double-layered target which increases its ballistic resistance compared with in-contact target configuration. The difference between the ballistic resistances of different double-layered target configurations may be diminshed at high impact velocity.

It can be concluded from the previous figures that the difference between the ballistic resistances of different double and triple-layered steel target configurations may be diminshed at high impact velocity. This conclusion is similar to that obtained by Almohandes et al. [8] who studied experimentally the effect of steel target configurations on their ballistic performance when they impacted by $7.62 \mathrm{~mm}$ standard bullets of different velocities.

Figure 5 plots the change of projectile velocity drop ratio $\left(\mathrm{DV} / \mathrm{V}_{\mathrm{i}}\right)$ with impact velocity for single, spaced and in-contact triple-layered steel targets having total thickness of $3 \mathrm{~mm}$. For each target configuration, it is seen from the figure that the velocity drop ratio always decreases with increasing impact velocity. The present figure also shows that the penetrator velocity drop ratio during its penetration to the in-contact triple-layered target is greater than that of single target of equal total thickness for $V_{i}>450 \mathrm{~m} / \mathrm{s}$. In 
addition, the spaced triple-layered targets has the lowest effect on penetrtor velocity drop ratio in comparison with the single and in-contact triple-layered targets of equal total thickness.

Figure 6 plots the change of penetrator residual velocity as function of target thickness ratio at average impact velocities of 350,448 and $558 \mathrm{~m} / \mathrm{s}$, respectively, for single and different configurations of spaced and in-contact double-layered steel targets, with total thickness of $3 \mathrm{~mm}$. The present figure shows that the ballistic resistance of the single target is slightly greater than that of the other double layered steel target configurations. In addition, the present figure determines the thickness ratio of double-layered steel targets that give maximum ballistic resistance; this thickness ratio is found to be 0.5 for spaced double-layered target at $\mathrm{V}_{\mathrm{i}}=350,448$ and $558 \mathrm{~m} / \mathrm{s}$, respectively.

Figure 7 depicts the change of residual velocity ratio as function of target thickness ratio at the average impact velocities used, respectively, for single and different configurations of spaced and in-contact double-layered steel targets, with total thickness of $3 \mathrm{~mm}$. The present figure confirms the thickness ratio of 0.5 for spaced double-layered targt that gives the highest ballistic resistance compared with that of other double-layered target configurations at the respective impact velocities.

Figure 8 plots the change of velocity drop ratio with no. of target layers for single, in-contact and spaced double $(2 \times 1.5 \mathrm{~mm})$ and triple $(3 \times 1 \mathrm{~mm})$ layered steel targets, having the same total thickness at different impact velocities. For each impact velocity, the present figure shows that the single target has the highest ballistic resistance compared with that of other double and triple-layered target configurations. In addition, the ballistic resistance of spaced double-layered target is greater than that of spaced and in-contact triplelayered targets except for $\mathrm{Vi}=558 \mathrm{~m} / \mathrm{s}$ where the resistance of in-contact triple-layered target is slightly greater than that of spaced and in-contact double-layered targets.

Figure 9 plots the change of velocity drop ratio with no. of target layers for single, in-contact and spaced double $(1 \mathrm{~mm}+2 \mathrm{~mm})$ and triple $(3 \times 1 \mathrm{~mm})$ layered steel targets, having the same total thickness at different impact velocities. For each impact velocity, Similar results as that presented in Fig. 8 for the ballistic resistance of single target in comparison with that of other double and triple-layered target configurations are obtained. In addition, the present figure shows that the ballistic resistance of in-contact triple-layered target is greater than that of spaced and in-contact double-layered targets at each impact velocity.

It can be concluded from the previous figures that the single target has the highest ballistic resistance compared with that of the other double and triple-layered target configurations. The spaced double-layered steel target with thickness ratio of 0.5 gives the highest ballistic resistance compared with that of other incontact double-layered targets as well as the spaced and in-contact triple-layered targets at $\mathrm{Vi}=350$ and $448 \mathrm{~m} / \mathrm{s}$, respectively. In addition, the ballistic resistance of in-contact triple-layered steel target is greater than that of different double-layered steel target configurations at $\mathrm{Vi}=558 \mathrm{~m} / \mathrm{s}$.

\section{Results of Post-Firing Examinations}

The recovered penetrators after perforating the single and different multi-layered steel targets over the used impact velocity range were examined. The perforated penetrators were not subjected to deformation (rigid) during each penetration process.

The visual inspection of single and each layer of different multi-layered steel target configurations after terminating the penetration process showed that the petalling failure mode was always occurred. The number of petals was ranged from five to six. The average petal heights of the perforated layers of each target configuration were ranged from 4-5 $\mathrm{mm}$. Moreover, the average of entrance diameters were ranged from 7-9 $\mathrm{mm}$ and the average exit diameters were ranged from 8-11 $\mathrm{mm}$.

\section{Comparison between Measured and Predicted Results of Autodyn-2D Hydrocode}

In the following, the experimental measurements obtained due to the perforation of different tested steel targets by small caliber penetrators at different impact velocities are compared with the predicted results of the Autodyn-2D hydrocode. Moreover, the absolute relative differences between the measured and predicted results are calculated. Autodyn-2D is run to predict the penetrator residual velocities after perforating the single and different spaced and in-contact multi-layered steel targets, with total thickness of $3 \mathrm{~mm}$. Penetrator length and its diameter as well as the data of each tested single or multi-layered steel target that fed to the hydrocode are listed in Table 1 . 
Figure 10 shows the predicted change of projectile residual velocity with impact velocity obtained by Autodyn-2D hydrocode for single, spaced and in-contact triple-layered steel targets, respectively. For each target configuration, the measured residual velocities corresponding to different impact velocities are also depicted on the same figure. Good agreement is obtained between measured and predicted residual velocities over the used range of impact velocity. In addition, the absolute maximum differences between the measured and predicted results of Autodyn-2D hydrocode for single, in-contact and spaced triplelayered steel targets are 14.6, 14.2 and $14.2 \%$ at measured impact velocities of 341,552 and $334 \mathrm{~m} / \mathrm{s}$, respectively.

Figure 11 also plots the measured and the corresponding predicted change of projectile residual velocity with impact velocity for single, spaced and in-contact double-layered steel targets, respectively. Good agreement is obtained between measured and predicted residual velocities over the used range of impact velocity. In addition, the absolute maximum differences between the measured and predicted results of Autodyn-2D hydrocode for single, in-contact and spaced double-layered targets are 14.6, 13.9 and $3.2 \%$ at measured impact velocities of 341,439 and $349 \mathrm{~m} / \mathrm{s}$, respectively. The obtained predictions prove the capabilities of Autodyn-2D hydrocode to be used as a tool for constructing the single, spaced or in-contact multi-layered steel targets capable of defeating a certain threat.

Figure 12 depicts the predicted change of penetrator residual velocity as function of target thickness ratio at average impact velocities of 350 and $448 \mathrm{~m} / \mathrm{s}$, respectively, for single and different configurations of spaced and in-contact double-layered steel targets, with total thickness of $3 \mathrm{~mm}$. The measured residual velocities are also depicted on the same figure. Both the predictions and experimental measurements for each double-layered steel target configuration are in good agreement at each impact velocity used. Moreover, both the measured and predicted results determine the thickness ratio of double-layered steel targets that gives the maximum ballistic resistance; this ratio is 0.5 for spaced configuration at $\mathrm{V}_{\mathrm{i}}=350$ and $448 \mathrm{~m} / \mathrm{s}$, respectively.

\section{CONCLUSIONS}

The following points could be drawn out from the present work:

(i) The ballistic resistance of single steel target is greater than the in-contact and spaced double and triple-layered steel targets of equal total thickness over the used impact velocity range except for $\mathrm{Vi}=$ $558 \mathrm{~m} / \mathrm{s}$ where the in-contact triple-layered target has the best ballistic resistance.

(ii) The difference between the ballistic resistance of different double and triple-layered target configurations may be diminshed at high impact velocity.

(iii) The spaced double-layered steel target with thickness ratio of 0.5 gives the highest ballistic resistance compared with that of other in-contact double-layered targets as well as the spaced and in-contact triple-layered targets at $\mathrm{Vi}=350$ and $480 \mathrm{~m} / \mathrm{s}$, respectively. In addition, the ballistic resistance of incontact triple-layered steel target is greater than that of different double-layered steel target configurations at $\mathrm{Vi}=558 \mathrm{~m} / \mathrm{s}$.

(iv) Good agreement is obtained between measured and predicted residual velocities over the used range of impact velocity for single and different double and triple-layered steel target configurations, respectively.

(v) Autodyn-2D hydrocode can be used as a tool for constructing the single, spaced or in-contact multilayered steel targets capable of defeating a certain threat.

\section{REFERENCES}

1. M.E. Backman and W. Goldsmith, "The Mechanics of Penetration of Projectiles into Targets", Int. J. Eng. Sci., Vol. 16, pp. 1-99 (1978).

2. A.J. Zukas, "Impact Dynamics", John Wiely \& Sons, New York, Ch. 5, pp. 157-210 (1982).

3. R.L. Woodward and M.E. De Morton, "Penetration of Targets by Flat Ended Projectiles", Int. J. Mech Sci., Vol. 8, pp. 119-127 (1976).

4. M. Ravid and S.R. Bodner, "Dynamic Perforation of Viscoplastic Plates by Rigid Projectiles" Int. J. Eng. Sci., Vol. 21, No. 6, pp. 577-591 (1983).

5. J. Liss, W. Goldsmith and J.M. Kelly, "A Phnomonological Penetration Model of Plates", Int. J. Impact Engng., Vol. 1, pp. 321-341 (1983).

6. A. Arias, J.A. Rodriguez and A. Rusinek, "Numerical Simulations of Impact Behaviour of Thin Steel Plates Subjected to Cylindrical, Conical and Hemispherical Non-Deformable Projectiles", J. 
Engng. Fracture Mech., Vol. 75, pp. 1635-1656 (2008).

7. T. Borvik, O.S. Hopperstad, M. Langseth and K.A. Malo,"Effect of Target thickness in Blunt Projectile Penetration of Weldex 470E Steel Plates", Int. J. Impact Engng., Vol. 28, pp. 413-464 (2003).

8. A.A. Almohandes, M.S. AbdeI-Kader and A.M. Eleiche, "Experimental Investigation of the Ballistic Resistance of Steel-Fiberglass Reinforced Polyester Laminated Plates", Elsevier Science Limited, Part B, pp. 447-458 (1996).

9. S. Dey, T. Borvik and X.Teng, "On the Ballistic Resistance of Double-Layered Steel Plates: An Experimental and Numerical Investigation", Int. J. Solids and Structures, Vol. 44, pp. 6701-6723 (2007).

10. N.K.Gupta and V. Madhu, "An Experimental Study of Normal and Oblique Impact of Hard-Core Projectile on Single and Multi-Layered Plates", Int. J. Impact Engng., Vol. 19, pp. 395-414 (1997).

11. G. Yossifon, A.L.Yarin and M.B.Rubin, "Penetration of a Rigid Projectile into a Multi-Layered Target: Theory and Numerical Computations", Int. J. Eng. Sci., Vol. 40, pp. 1381-1401 (2002).

12. A.L. Yarin, M.B. Rubin and I.V. Roisman, "Penetration of a Rigid Projectile into an Elastic-Plastic Targets of Finite Thicknesses", Int. J. Impact Engng., Vol. 16, pp.801-831 (1995).

13. R.L.Woodward and S.J. Cimpoeru, "A Study of the Perforation of Aluminum Laminate Targets", Int. J. Impact Engng., Vol. 21, pp. 117-131 (1998).

14. C. Liang, M. Yang, P. Wu and T. Teng, "Resistant Performance of Perforation of Multi-Layered Target Using an Estimation Procedure with Marine Application", Ocean Engng, Vol. 32, pp. 441468 (2004).

15. P.Myungsoo, J. Yoo and D.T. Chung, "An Optimization of a Multi-Layered Target Under Ballistic Impact", Int. J. Solids and Struc., Vol. 42, pp. 123-137 (2005).

16. "AUTODYN Theory Manual", Revision 3.0, Century Dynamics Inc. (1997).

Table 1. Input data of penetrator and each thickness of plate material to Autodyn-2D hydrocode.

\begin{tabular}{|c|c|c|c|c|c|}
\hline \multirow{2}{*}{ Parameter } & \multirow{2}{*}{ Penetrator } & \multicolumn{4}{|c|}{ Plate material thickness, [mm] } \\
\hline & & 1 & 1.5 & 2 & 3 \\
\hline - Reference density, $\left(\mathrm{g} / \mathrm{cm}^{3}\right)$ & 7.87 & \multicolumn{4}{|c|}{7.81} \\
\hline - Reference temperature, $\left({ }^{\circ} \mathrm{K}\right)$ & 300 & \multicolumn{4}{|c|}{300} \\
\hline - Penetrator length, $(\mathrm{mm})$ & 23 & \multicolumn{4}{|c|}{-} \\
\hline - Penetrator diameter, $(\mathrm{mm})$ & 6.24 & \multicolumn{4}{|c|}{-} \\
\hline - Plate surface dimensions, $\left(\mathrm{mm}^{2}\right)$ & - & \multicolumn{4}{|c|}{$200 \mathrm{~mm} \times 200 \mathrm{~mm}$} \\
\hline - Specific heat (C.V.), (J/kg. $\left.{ }^{\circ} \mathrm{K}\right)$ & 475 & \multicolumn{4}{|c|}{448} \\
\hline -Shear modulus, $(\mathrm{GPa})$ & 80 & \multicolumn{4}{|c|}{80} \\
\hline - Yield stress (MPa) & 1500 & \multicolumn{4}{|c|}{305} \\
\hline - Elasticity modulus, $(\mathrm{GPa})$ & 220 & \multicolumn{4}{|c|}{201} \\
\hline - Strain rate constant & 0.014 & \multicolumn{4}{|c|}{0.022} \\
\hline - Melting temperature, $\left({ }^{\circ} \mathrm{K}\right)$ & 1537 & \multicolumn{4}{|c|}{1537} \\
\hline - Erosion strain & - & \multicolumn{4}{|c|}{1.0} \\
\hline
\end{tabular}

Figures:

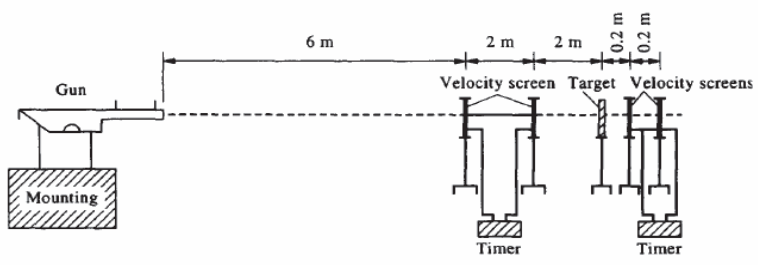

Fig.1. A scheme of ballistic test steup.
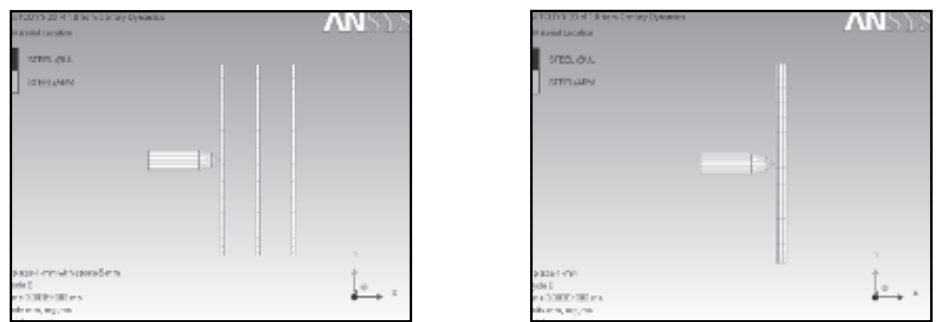
Fig. 2. Simulation of hard steel penetrator against triple-layered steel targets,

(a) spaced and (b) in-contact.

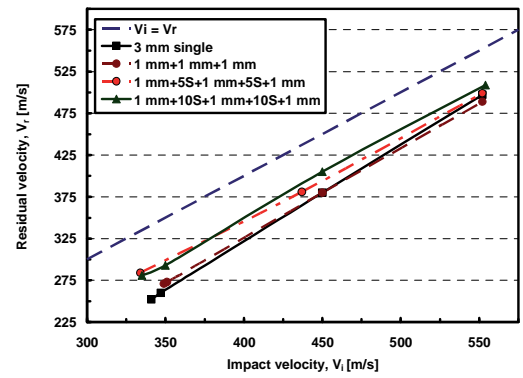

Fig. 3. Change of residual velocity with impact velocity for single, in-contact and spaced three-layered targets, having the same total thickness.

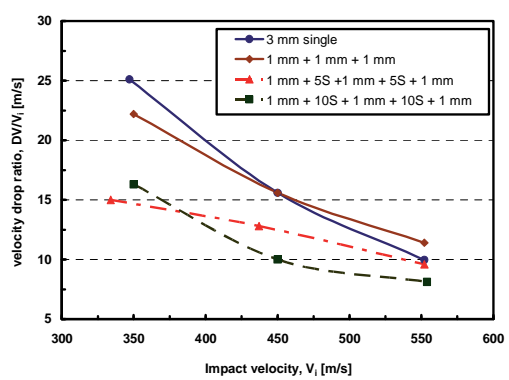

Fig. 5. Change of velocity drop ratio with impact velocity for single, in-contact and spaced three layered targets, having the same total thickness.

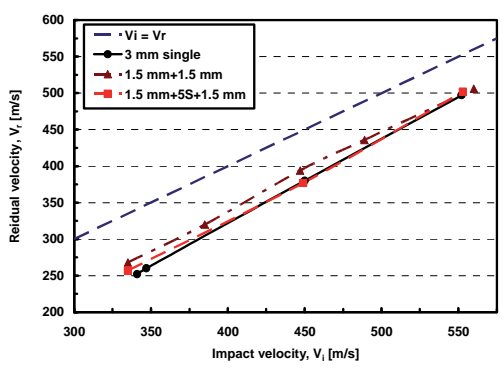

Fig. 4. Change of residual velocity with impact velocity for single, in-contact and spaced double-layered steel targets having the same total thickness.

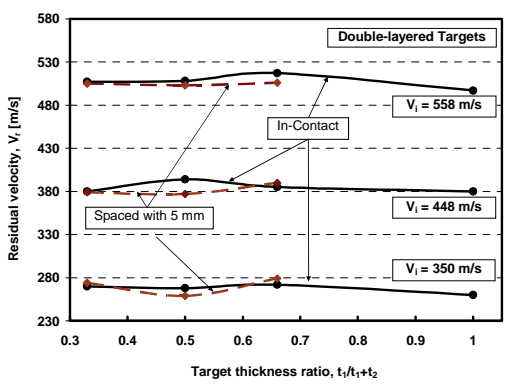

Fig. 6. Change of residual velocity with target thickness ratio for single, in-contact and spaced double layered targets, having the same total thickness at different impact velocities. 


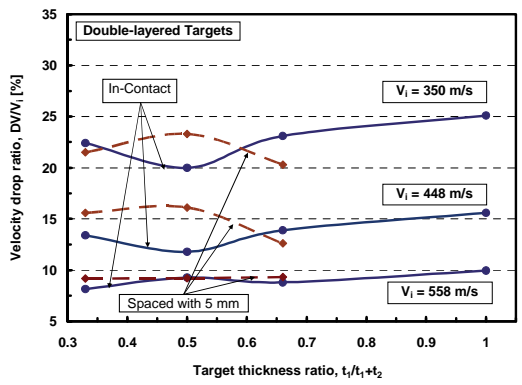

Fig. 7. Change of velocity drop ratio with target thickness ratio for single, in-contact and spaced double-layered targets, having the same total thickness at different impact velocities.

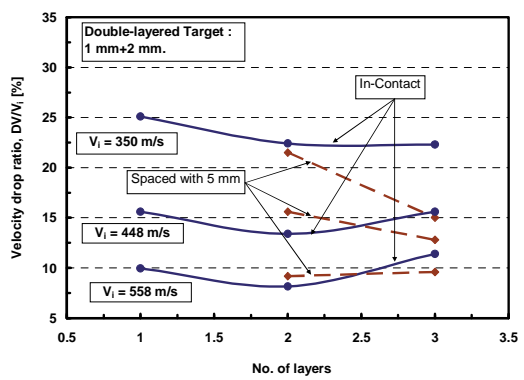

Fig. 9. Change of velocity drop ratio with no. of target layers for single, in-contact and spaced double and three-layered targets, having the same total thickness at different impact velocities.

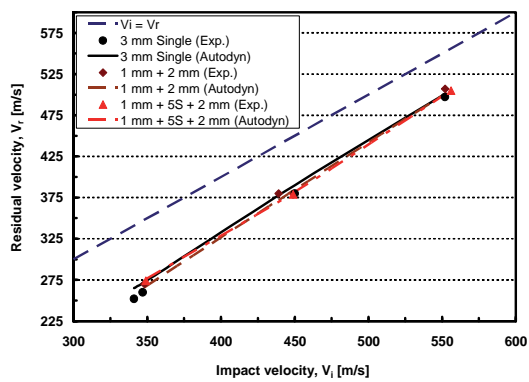

Fig. 11. Comparison between Autodyn-2D predictions and experimental measurements due to the change of residual velocity with impact velocity for single and double-layered targets.

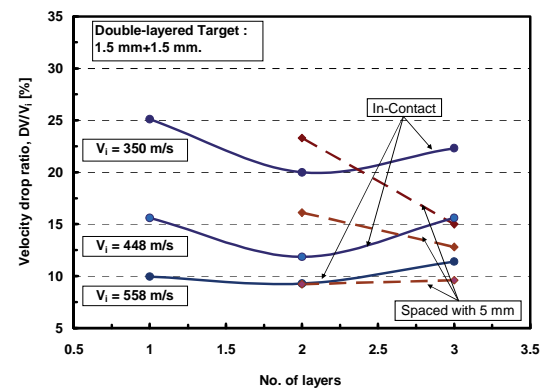

Fig. 8. Change of velocity drop ratio with no. of target layers for single, in-contact and spaced double and three-layered targets, having the same total thickness at different impact velocities.

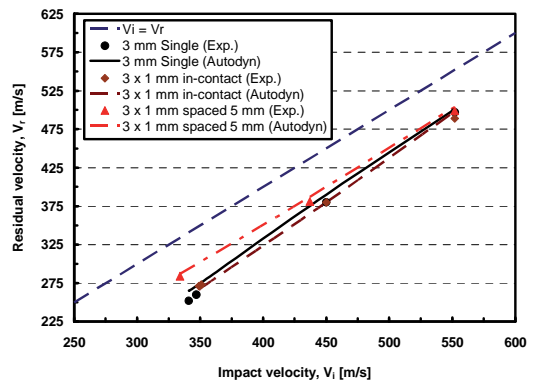

Fig. 10. Comparison between Autodyn-2D predictions and experimental measurements due to the change of residual velocity with impact velocity for single and three-layered targets.

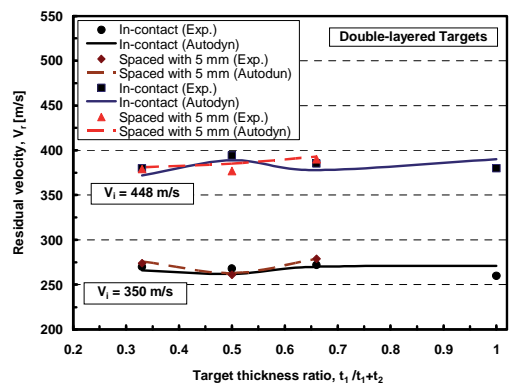

Fig. 12. Comparison between Autodyn-2D predictions and experimental measurements due to the change of residual velocity with target thickness ratio for single and double-layered targets at different impact velocities. 